\title{
El sistema de protección de las personas mayores en el Derecho francés: diversificación y proporcionalidad de las medidas
}

\author{
The system of protection of the elderly with disabilities in French law: diversification \\ and proportionality of measures
}

\section{Daniela Jarufe Contreras}

\section{Resumen}

Esta investigación tiene por objeto principal dar a conocer el modelo legal de protección de las personas mayores en el Derecho francés en el que, a partir de la ley № 2007-308 de 5 de marzo de 2007 (cuya entrada en vigor fue en el año 2009 y que modifica principalmente las normas del Código civil) ha operado una transformación sustancial desde aquella concepción únicamente médica o asistencial de la discapacidad (aún vigente en nuestro país) a una visión social- jurídica, que exige el respeto de la autonomía y la conservación de la capacidad jurídica de las personas, todo lo posible; previendo, sin embargo, determinadas limitaciones (necesarias y razonables) de la capacidad de obrar que no significan, creemos, un atentado a la personalidad jurídica del mayor vulnerable.

Palabras-clave: Protección de mayores. Discapacidad. Capacidad.

\section{Abstract}

The main purpose of this research is to disclose the legal model for the protection of the elderly in French law in which, based on Law No. 2007-308 of March 5, 2007 (whose entry into force is from the year 2009 and that mainly modifies the norms of the Civil Code) has brought about a substantial transformation from that only medical or welfare conception of disability (still in force in our country) to a social-legal vision, which demands respect for autonomy and the conservation of the legal capacity of persons, as much as possible; foreseeing, however, certain limitations (necessary and reasonable) of the capacity to act that does not mean, we believe, an attack on the legal personality of the most vulnerable.

Keyword: Elder protection. Disability. Capacity.

\section{Introducción}

Una afirmación previa y fundamental es que para proteger a una persona con discapacidad ${ }^{1}$, esta no debe ser declarada incapaz. Sólo a partir de tal ineludible premisa creemos que se interpretan de manera adecuada los principios establecidos en la Convención de las Naciones Unidas de los Derechos de Personas con Discapacidad² y, en particular, lo dispuesto en el artículo 12 de la misma (MARTíNEZ DE AGUIRRE, 2014, p. 87-88)³. Sin embargo, no toda restricción de la capacidad de obrar, significa en sí mismas una contravención al art. 12 de la Convención ni mucho menos una discriminación, según explicaremos.

* Doctora en Derecho y Magíster (con suplemento europeo) por la Universidad de Zaragoza (España); Académica e investigadora de Derecho Civil de la Facultad de Ciencias Jurídicas y Sociales de la Universidad de Talca (Chile). Este trabajo se publica en el marco del proyecto de investigación Fondecyt de Iniciación No11190924 (IR). E-mail: djarufe@jarufeyasociados.cl.

Nos referimos a las personas con discapacidad psíquica o intelectual, único ámbito en el que podría discutirse acerca de su capacidad en términos jurídicos. Asimismo, cuando hablamos de capacidad, nos referimos a la capacidad de obrar o capacidad de ejercicio (entendida como la posibilidad de actuar por sí solo en la vida del Derecho, sin el ministerio o autorización de otro y no a la reconocida como capacidad de goce (que corresponde a toda persona por el solo hecho de ser tal). Lo anterior aunque, según veremos, en el ámbito internacional se utiliza el concepto de "capacidad jurídica" comprensiva, en interpretación del Comité de los Derechos de las personas con discapacidad, tanto de la capacidad de goce como de ejercicio.

2 Adoptada por la Asamblea General de las Naciones Unidas el 13 de diciembre de 2006. En adelante, indistintamente así llamada, o "la Convención", o CIDPD.

3 Y ello, entre otras cosas, porque "...hay incapacitados que tienen una capacidad muy superior a la de muchos menores de edad, o en los que la incapacitación se traduce en la sujeción de determinados actos patrimoniales, especialmente importantes, a la asistencia de un curador; en estos casos hay incapacitación legal, pero no se produce esa privación radical de la capacidad de obrar que parece traslucir la palabra empleada por la ley". 
Así, el objetivo de este trabajo es demostrar a través de la legislación francesa, que la clave de un sistema de apoyo (que no necesariamente de sustitución de voluntad) radica precisamente en no restringir ni abolir a priori la capacidad de obrar; salvo que así lo exija el interés del sujeto de protección4.

De cara a ello, presentaremos algunos aspectos generales del sistema de protección del Derecho francés ${ }^{5}$, tales como la legislación vigente, las principales instituciones de protección del Derecho francés y el desarrollo de algunos conceptos indispensables como son la "vulnerabilidad", la "capacidad" y la "discapacidad". Luego, expondremos y analizaremos de manera crítica los principios inspiradores de dicha legislación a modo de justificar su adecuación al art. 12 de la Convención y también haremos alusión a las observaciones que ha realizado en este sentido el Comité 6 . Terminaremos con algunas reflexiones que servirán en si mismas como conclusión`. En todo momento, así como haremos alusión a los aspectos positivos a destacar, también nos referiremos a aquellas falencias detectadas por la doctrina en esta materia.

Elegimos en esta ocasión el Derecho francés ${ }^{8}$ porque creemos que es una de las legislaciones, aunque en muchos aspectos perfectible, más acordes a los tratados internacionales y los principios actuales que éstos promueven en relación con la protección de las personas con discapacidad, según intentaremos demostrar en cada uno de los apartados de este trabajo (BARRANCO; CUENCA; RAMIRO, 2012, pp. 53-80)․

Quizás la justificación más noble de este trabajo, esté dada por la posibilidad que otorgaremos al lector de conocer un sistema complejo que requiere no solo de una revisión concienzuda y exhausta, sino de la comprensión y sistematización adecuada de un importante número de cuerpos normativos, de doctrina y de jurisprudencia especializada, no siempre de fácil acceso y que significan, como es evidente, un manejo del derecho civil y del idioma galo ${ }^{10}$.

\section{Aspectos generales relativos a la protección de la personas adultas en el derecho francés}

La situación de las personas con discapacidad estaba antes prevista en la ley $\mathrm{N}^{\circ} 75-543$ de 30 de junio de 1975; y principalmente regida por la ley № 2005-102 de 11 de febrero de 2005 relativa a la igualdad de derechos y de oportunidades en la participación y la ciudadanía de las personas con discapacidad, que modificó sustancialmente numerosos artículos del Código de Acción Social y de las Familias; el Código del Trabajo, el Código de Salud Pública, y el Código electoral, entre otros. Es la ley № 2007-308 de 5 de marzo la que completa tales disposiciones, cuya entrada en vigor es de 1 de enero del año 2009 y que reforma el régimen de protección de mayores (CARON-DÉGLISE, 2016, p. 1-5).

En cuanto al Código civil francés", son los títulos IX, X y XI del libro dedicado a "las personas" los que han reglamentado las principales instituciones que están relacionadas con la incapacidad: autoridad parental, tutela , protección de mayores, etc.

Dispone el art. 425 del Ccf que toda persona que no pueda velar por sí sola de sus intereses en razón de una alteración, médicamente constatada ${ }^{12}$, ya sea de sus facultades mentales o corporales de naturaleza tal que le impidan la expresión de su voluntad puede beneficiarse de una de las medidas de protección jurídica de las

4 Este es un tema recurrente y muy discutido en cuanto a la extensión de la autonomía de las personas con discapacidad Si bien no lo desarrollaremos in extenso en este trabajo, nos referiremos a ello al tratar los principios de proporcionalidad y de igualdad, y también en el apartado dedicado al art. 12 de la Convención Internacional de Derechos de las Personas con Discapacidad.

5 Si bien el sistema de instituciones de protección en el derecho francés reconoce como destinatarios a tres grupos de personas: los menores de edad; los menores de edad emancipados y los mayores de edad; nos centraremos sólo en los mayores de edad y, particularmente, en los mayores de edad con alguna discapacidad intelectual.

6 El Comité sobre los Derechos de las Personas con Discapacidad es un órgano de expertos en derechos humanos encargados de la vigilancia de la aplicación de la Convención. En atención al mandato establecido en el art. 35 de la CIDPD, se dispone la obligación de los Estados parte de presentar ante el Comité informes exhaustivos sobre las medidas que hayan adoptado para cumplir con la Convención y sobre los progresos realizados al respecto en el plazo de dos años contado a partir de su entrada en vigor.

7 Sólo haremos algunas breves alusiones a otros ordenamientos jurídicos, cuando aparezca como necesario y se estime que puedan servir de ejemplo o advertencia para aquellos países que estamos recién comenzando un camino de evolución hacia un sistema más justo de protección de mayores y de tratamiento de la discapacidad.

8 En trabajos anteriores hemos analizado el Ordenamiento jurídico español y posteriormente se analizará el sistema suizo de capacidad.

Creemos, que se trata de un modelo social que "desgarra el velo" que justificaba la exclusión total de las personas con discapacidad.

10 Todas las traducciones han sido hechas por quien escribe, salvo aquellas que cuentan con un texto oficial en español y que se indicarán en su caso.

En adelante Ccf.

12 Puede parecer, a primera vista, que se trata de un requisito. Mas, como veremos posteriormente, no es ese el sentido de la norma. Sin embargo, estamos de acuerdo en que no parece adecuada la mención de la constatación médica en el Código civil. 
que se prevén en el capítulo "de las medidas de protección jurídicas de los mayores" (capítulo II del título XI). Las principales medidas son la salvaguarda judicial, la tutela, la curatela y el mandato de protección futura.

La salvaguardia de la justicia está prevista en el art. 433 del Ccf y se orienta a aquella persona que, estando en algunas de las circunstancias previstas en el art. 425, se encuentra en la necesidad de una protección temporal de ser representada únicamente para un acto determinado. Puede tratarse de una medida proseguida de una curatela o de una tutela si las circunstancias que le dieron lugar se extienden en el tiempo. La curatela se consagra entre los artículos 440 y siguientes del Ccf y se prevé respecto de aquella persona que, sin poder actuar por sí mismo necesite, por alguna de las causas previstas en el artículo 425, ser asistido o supervisado continuamente en los actos importantes de la vida civil. Se determina esta medida únicamente cuando la salvaguardia de la justicia no aparezca como suficiente para el resguardo de los intereses de la persona protegida. La tutela, por su parte, es más bien de carácter residual, y solo tiene lugar en aquellas circunstancias en las que habiéndose intentado las demás medidas, ninguna de ellas ha servido a los efectos que se requieran, según el estado y circunstancias de cada persona ${ }^{13}$. Es el mismo art. 440 del Ccf el que dispone que si la persona requiere ser representada de una manera continua en los actos de la vida civil puede ser puesta bajo dicha medida ${ }^{14}$. Finalmente, el mandato de protección futura (tratado a partir del art.477 del Ccf) es una medida de carácter voluntario (no judicial) en virtud del cual toda persona que no sea objeto de una medida de tutela o de una habilitación familiar puede encargarle a una o más personas su representación previendo que se encontrará, en el futuro, en alguna de ls situaciones contempladas en el ya mencionado art. 425 del Ccfis. Habrá que consultar, además los artículos L. 3212- L. 3216, L. 3221del Código de Salud Pública (en adelante Csp); y los arts. L.114, L.146, L.149, L.241- L.247 del Código de Acción Social y de las Familias (en adelante Casf); además de los artículos del Código de Procedimiento Civil francés (en adelante $\mathrm{Cpc}$ ) todos los cuales se mencionarán a lo largo de este trabajo.

\subsection{La noción de vulnerabilidad y su interpretación en el Derecho francés}

A saber, la palabra vulnerabilidad proviene del latín "vulnerabilis"; de la noción "vulnerare" que significa en estricto rigor "herida". El Diccionario oficial de la lengua española designa con el adjetivo "vulnerable" a cualquiera que sea susceptible de ser herido o de padecer una lesión psíquica o moral (ESTUPIÑAN-SILVA, 2014, p, 89-113).

La vulnerabilidad es una noción que ha invadido nuestro entorno en los últimos años y el Derecho no es la excepción: coloquios, simposios, investigaciones, políticas sociales y sentencias han sido escenario de este concepto difícil de definir y que, sin embargo, es el eje central de todo sistema de protección (BURGORGUE, 2014, p. 7) 16. $^{16}$

Como muchas de las nociones metafóricas, la vulnerabilidad es un concepto variable. No todas las personas mayores son vulnerables y no todas las personas con discapacidad son siempre vulnerables. Los miembros de estas categorías ( $y$, por supuesto, de otras) solo serán vulnerables bajo ciertas circunstancias, en ciertos momentos y en determinados contextos sociales.

Por su parte, si bien las personas vulnerables son frágiles, no podemos decir que es lo mismo fragilidad que vulnerabilidad; si bien las personas vulnerables son también dependientes, tampoco es lo mismo dependencia que vulnerabilidad. No debe tampoco confundirse la vulnerabilidad con la noción de dignidad (ser vulnerable no significa la pérdida de la dignidad) (DENIZEAU, 2014, p. 117-150)17-18, ni con el concepto de desventaja o de inseguridad (BESSON, 2014, p. 59-85). Lo único cierto es que las personas vulnerables se identifican con aquellas que por distintas condiciones (que puede ser la edad, una enfermedad, $u$ otro factor) requieren de una protección especial

13 Nos referiremos a lo largo de este trabajo constantemente a la curatela y a la tutela, quedando en evidencia que esta última no constituye ni la regla general ni se aplica (o debiera aplicarse) sino en subsidio de cualquier otro mecanismo de protección menos lesivo. Más allá de si se denomina o no tutela, lo realmente relevante es la necesidad de representación de aquellos que, bajo ningún apoyo, podrán conocer y querer y, por tanto, manifestar libre y voluntariamente su voluntad.

14 Es importante señalar que el curador, a diferencia de lo que ocurre en Chile, no tendrá nunca facultades de representación, como sí ocurre en cambio con la tutela. Desde ese punto de vista, la tutela ha sido fuertemente criticada según veremos posteriormente, entendiendo que la interpretación que ha realizado el Comité respecto del art. 12 de la Convención implica eliminar toda forma de representación.

15 No nos referiremos en este trabajo a las medidas de carácter voluntario, sino únicamente a aquellas que son de carácter judicial.

16 Se explica como el fenómeno de la vulnerabilidad ha ido tomando lugar en el mundo y el desarrollo que ha tenido en las últimas décadas.

17 El filósofo KEMP señala que la persona vulnerable es un ser humano cuya autonomía, dignidad e integridad exigen protección en razón de su fragilidad y considera que no puede separarse la noción de vulnerabilidad ni de la autonomía ni de la integridad.

18 Según el autor, es uno de los primeros "derechos" que debe garantizarse a las personas vulnerables. 
y más intensa por parte del legislador, a fin de permitir el ejercicio de sus derechos en igualdad de condiciones con los demás; y que aquella cualidad no implica ni una connotación negativa ni mucho menos discriminatoria.

Así, se designa como vulnerable a aquella persona marcada por una fragilidad estructural, de orden psicológico o social que no le permite vivir de manera plenamente autónoma y que se ve expuesta a una amenaza o abuso

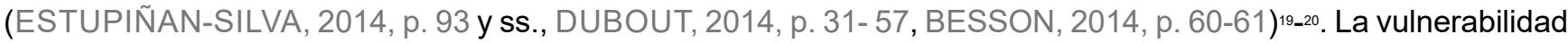
sobrepasa la idea de la necesidad de ayuda (ESTUPIÑAN-SILVA, 2014, p. 90). Aunque no signifique lo mismo, la vulnerabilidad parece afectar a personas de alguna manera heridas o débiles, ya sea por naturaleza (en el caso de los menores, de las personas con discapacidad, y de los extranjeros, por ejemplo) o ya sea porque han sido calificados como tales (como la mujer en determinadas circunstancias) (DENIZEAU, 2014, p. 124) ${ }^{21}$.

La Corte Europea de Derechos Humanos vincula la vulnerabilidad con la prohibición de discriminación. Se utiliza como criterio dinámico para la identificación de una lista, aunque no exhaustiva, de grupos a proteger. De este modo, parece que la vulnerabilidad constituye un medio (aunque no el único) para determinar los nuevos grupos respecto de los cuales no puede existir discriminación (transexualidad, orientación sexual y, por supuesto, discapacidad) (BESSON, 2014, p. 73 y ss., CARBONNIER, 2017, p. 624-625).

En Francia, si consideramos (como se ha dicho) que la vulnerabilidad implica la "debilidad" de un individuo, podemos encontrar la presencia implícita de la noción en el preámbulo de la Constitución de 1946: la demanda de asilo, el tratamiento especial de la infancia, de la madre y del trabajador añoso; todos ellos son objetos de una protección específica en razón precisamente de su vulnerabilidad ${ }^{22}$. Esta noción es de carácter individual y no general (inherente a todos los individuos), lo que consideramos un acierto ya que, en palabras de LAGARDE: la vulnerabilidad no es el solo "riesgo" de verse expuesto a un daño; y una concepción global de la misma, que conduzca a considerar como tales solo a quienes se encuentren bajo el ángulo de una exposición al riesgo sería un error (DENIZEAU, 2014, p. 144). Sin embargo, se puede constatar que no es la vulnerabilidad en el derecho francés una noción operativa, que no tiene una consistencia jurídica neta y que no existe una unidad conceptual de la misma. Es este, por tanto, otro de los denominados "conceptos jurídicos indeterminados".

\section{Relación de conceptos: capacidad, incapacidad, incapacitación discapacidad}

En términos generales, no es lo mismo hablar de "incapacitado" que de "incapaz". Dentro de los incapaces están los incapacitados, pero no todos los incapaces lo son. Lo anterior equivale a decir que no todo incapaz ha sido declarado como tal a través de un procedimiento judicial, sino que muchas veces es la ley la que le otorga a priori esta condición, como ocurre por ejemplo con los menores de edad. Por tanto, todo incapacitado es un incapaz, más no todo incapaz ha sido judicialmente incapacitado. La incapacitación total viene acompañada de la privación de la capacidad de obrar, a través de un procedimiento judicial que, en el caso del derecho francés, se restringe únicamente a la tutela, según veremos, bajo la cual incluso se mantiene por parte del protegido el poder de celebrar ciertos actos como los denominados estrictamente personales (como son el reconocimiento de un hijo, el testamento, etc) (BARRANCO; CUENCA; RAMIRO, 2012, p. 53-80)23.

19 Una "amenaza" es definida por la Corte Interamericana de Derechos Humanos como una violación convencional alegada por la presunta víctima (entiéndase violación de los derechos fundamentales). La Corte, igualmente, ha reconocido a la persona con discapacidad como un sujeto con un nivel mayor de riesgo de verse expuesto a la violación de sus derechos; ya sea en materia de trato igualitario, acceso a la justicia, derecho a tratamientos médicos, etc. (p. 102).

20 En el mismo sentido define BESson la vulnerabilidad, señalando que, en términos generales, se trata de la cualidad de un individuo o de un grupo susceptible de ser objeto de un atentado a sus intereses. Señala que es de tal importancia la vulnerabilidad para la Corte Europea de Derechos Humanos que ello explica el por qué no ha querido nunca definirla ni justificar su función.

21 En la sociedad ciertos individuos son vulnerables por naturaleza y todos los demás pueden encontrarse cualquier día en una situación de vulnerabilidad; y, en tal sentido, la vulnerabilidad es una probabilidad que el Derecho debe tomar en cuenta. En la página siguiente, el autor denuncia que el concepto de vulnerabilidad es prácticamente ignorado por los jueces tanto franceses como del Reino Unido, y que es más utilizado en el ámbito del Derecho penal que en el Derecho de familia o de la persona.

22 Aún más, se indica que todo ser humano que, en razón de su edad, de su estado físico o mental o de la situación económica se encuentre en la incapacidad de trabajar, tiene derecho a obtener de la colectividad los medios que convengan a su existencia. Traducción del inciso II, frase segunda del Preámbulo de la Constitución Francesa.

23 Tradicionalmente se ha entendido que la incapacitación (a lo menos total) significa un estatus de incapacidad de obrar y, por tanto, una restricción general de la aptitud que se presupone a toda persona para ejercer libremente sus derechos fundamentales. Esto, si bien es inaceptable en un estado de sano juicio, creemos que es incluso razonable en una situación de discapacidad que impida el autogobierno (discapacidad que, por cierto, no es dada por el legislador, sino que por la naturaleza o algún evento externo que afecta la vida de la persona con discapacidad). 
En Francia, la denominada capacidad jurídica (capacité juridique) es la aptitud de una persona para ser titular de derechos y ejercerlos por sí mismo. Ella se compone de la capacidad de goce (capacité de jouissance) y la capacidad de ejercicio (capacité d'exercice) (MALAURIE, 2016, p. 240-251, KJAERUM, 2016, p. 9) ${ }^{24}$. Se reconoce a todos la capacidad de goce, como un atributo de la personalidad jurídica, y únicamente puede ser restringida de modo parcial con relación a determinados derechos como ocurre, por ejemplo, en el caso de los extranjeros sin derecho a voto (CARBONNIER, 2017, p. 542 y ss., MALAURIE, 2016, p. 233) 25. La incapacidad de ejercicio, por su parte, es destinada a la protección de la persona que es privada de la capacidad de obrar: es el caso, por ejemplo, de un menor o el de una persona con discapacidad siempre que el estado de salud de esta, según veremos, amerite la restricción (o abolición) de su capacidad ${ }^{26}$ y exista un proceso a través del cual se le deniegue el ejercicio de ciertos derechos o la celebración de determinados actos o contratos ${ }^{27}{ }^{28}$.

El Código civil francés prevé en su art. 414 el principio de capacidad de los mayores (18 años), para celebrar actos jurídicos válidos, no obstante la posibilidad de obtener la anulación de este, si se demuestra que ha existido una perturbación mental al momento de su celebración (MOLIN, 2017, p. 18-19, VOIRIN; GOUBEAUX, p. 239-240, TEYSSIE, 2016, p. 392 y ss., MALAURIE, 2016, p. 239 y ss. $)^{29}$. La carga de la prueba pesa, como es evidente, sobre quien alega la perturbación ${ }^{30}$. La acción de nulidad, según lo dispone el art. 412 del mismo Código corresponde solo al interesado, de modo que entendemos que se trata de una sanción de nulidad relativa destinada a la protección de quien haya celebrado el acto o contrato (CARBONNIER, 2017, p. 546, MALAURIE, 2016, p. 243-244)31.

La discapacidad, por su parte, es definida por la ley $N^{\circ}$ 2005-102 de 11 de febrero de 2005 que crea el art. L. 114 del Código de la Acción Social y de las Familias, como toda limitación de actividad o restricción de participación en la vida en sociedad sufrida en su entorno por una persona, en razón de una alteración sustancial durable o definitiva de una o de varias de sus funciones psíquicas, sensoriales, mentales, cognitivas o físicas de una multidiscapacidad (entendida, creemos, como la alteración de varias de las funciones anteriores a la vez), o de una alteración invalidante de su salud.

Es importante destacar, y ello de cara a las posibles modificaciones que se realicen en nuestro Ordenamiento jurídico que en Francia, si bien se excluye a las personas con discapacidad de la responsabilidad penal, la responsabilidad civil en determinados casos subsiste (art.489-2) (CARBONNIER, 2017, p. 637 y ss.)32.

24 Hacemos este alcance porque no todos los ordenamientos jurídicos hacen la misma distinción, lo cual acarrea problemas, y en lo que ahora nos interesa, a la hora de determinar a qué capacidad de refiere realmente la Convención. En España, por ejemplo, se habla de "capacidad jurídica" para identificar la posibilidad de ser titular de derechos y deberes (lo que nosotros entendemos como capacidad de goce y que es, precisamente, el atributo de la personalidad) y se conoce como "capacidad de obrar" lo que nosotros denominamos "capacidad de ejercicio" y que también puede encontrarse en algunos textos extranjeros como la "capacidad de obrar", razón por la cual la denominamos así en este trabajo. Por su parte, téngase en cuenta que no existe ninguna definición internacional de la capacidad jurídica.

25 Es incapaz de goce, entonces, aquel que no puede ser titular de derechos. Téngase en cuenta, sin embargo, que a partir ya de la ley del año 1968 el legislador ha eliminado prácticamente la voz "incapaz" para hablar más bien de "personas protegidas", diferenciación que cobra importancia en el ámbito de los mayores protegidos ya que no todos ellos son incapaces, como ya se ha dicho.

26 En adelante, cuando me refiera a la "capacidad" a solas, nos estaremos refiriendo a la capacidad de ejercicio (o llamada también capacidad de obrar).

27 Proceso que puede o no significar su incapacitación (total).

28 Cuestión que no ocurre en Chile, por ejemplo, con el llamado "demente" por el art. 1447 el Código Civil chileno "Son absolutamente incapaces los dementes, los impúberes y los sordos o sordomudos que no pueden darse a entender claramente. Sus actos no producen ni aun obligaciones naturales, ly no admiten caución" Es el demente, por tanto, un incapaz sin necesidad de ser incapacitado, por el sólo hecho de la discapacidad mental, cuya prueba deberá ejercerse a posteriori en el evento de solicitarse la nulidad del acto que haya celebrado (la interdicción sólo vale como medio de prueba). Vale decir, un menor (entre 0 y 12 años mujer y 14 años varón) y un demente, desde el punto de vista de la capacidad de obrar, en Chile tienen el mismo tratamiento legal (cuestión que es impresentable ante los principios de la Convención).

29 Aunque no siempre las facultades mentales alteradas del autor autorizan la anulación. La fecha en que sea demandada, tendrá una gran importancia. La prescripción de la acción, es de 5 años según lo prevé el art. 1304 del mismo Código, no obstante habrá que distinguir si se trata de un mayor protegido o no protegido. En el primer caso, el plazo se computa desde el día en que éste haya tenido conocimiento del acto y lo pueda "rehacer válidamente" (expresión que si bien genera problemas de interpretación en la doctrina y la jurisprudencia francesa, ha sido entendida como una alusión a aquel momento en el que cese la medida de protección); mientras que en el segundo caso el plazo se cuenta desde la celebración del acto o contrato que se pretende anular.

30 De la interpretación armónica del Ccf y las leyes relativas a la protección del mayor, se desprende que el legislador utiliza la palabra "trouble" para referirse no sólo a un trastorno de carácter grave, sino a cualquier trastorno o perturbación que pudiere incidir en una declaración de voluntad libre y espontánea. Es importante esta aclaración, pues si el lector busca el significado de "trouble" en el diccionario, podría imaginar, sin conocer la historia de la ley ni el Ordenamiento jurídico francés, que se trata de un grado determinado de enfermedad mental, cuestión que no es acertada. Véase asimismo lo que señala el diccionario francés Le Nouveau Petit Robert, en el que se define un trastorno sin alusión a la gravedad de este, e incluso sin hacer alusión exclusiva a las facultades mentales: "Modification pathologique des activités de l'organisme ou de comportement (physique ou mental) d l'être vivant".

31 Evidentemente, y según lo señala el art. 468, inciso III del Ccf, dependiendo de sus facultades, es una acción que puede ser también entablada por el tutor, o por el mismo afectado con la asistencia de su curador.

32 Lo mismo ocurre, por ejemplo, en el Ordenamiento jurídico español. El nuevo Código civil, cuya entrada en vigor data de junio del presente año (2021) si bien elimina la incapacitación, mantiene la responsabilidad civil de aquellas personas que requieren de apoyo para la toma de decisiones (véase art. 299 del Código civil español). 
Por último, y a fin de aclarar todos los conceptos, la vejez si bien es una causa frecuente de incapacitación, no entraña en sí misma la alteración de las facultades mentales ni tampoco la pérdida de la independencia. El sólo hecho de ser anciano no significa ser ni persona con discapacidad ni incapacitado. Si el anciano tiene una discapacidad que altera sus aptitudes para entender y querer, debe entonces ser protegido y es allí cuando se activan los mecanismos de apoyo a la capacidad, más o menos intensos, según corresponda (MALAURIE, 2016, p. 292-293).

\section{Principios que inspiran el sistema de protección de mayores en el Ordenamiento Jurídico francés ${ }^{33-34}$}

Como afirma Molin, mientras la ley № $68-5$ de 3 de enero de 1968 ${ }^{35}$, era una legislación de protección más bien patrimonial del "incapaz"; la actual ley de 5 de marzo de 2007 es una ley de "libertad" que reafirma los principios fundamentales aplicables a los mayores protegidos (MOLIN, 2017, p. 20-21, BAUDIS, 2012, 2021, p. $31)^{36}$, y que se plasman en los actuales artículos del Ccf. Así, el art. 415, inciso II, señala precisamente que las medidas de protección serán instauradas en un contexto de respeto de las libertades individuales, de los derechos fundamentales y de la dignidad de la persona. Por su parte, el art. 425, inciso II pone de manifiesto que las medidas contenidas en el Ccf. están destinadas no sólo a la protección del patrimonio del protegido, sino también a su persona, no obstante pueda el juez de tutelas (MALAURIE, 2016, p. 252-253, DEFENSEUR DES DROITS, 2016, p. 39) ${ }^{37}$, como excepción debidamente justificada, limitar la medida ya sea exclusivamente a la protección de los bienes, ya sea exclusivamente de la persona (CARBONNIER, 2017, pp. 652-653, MALAURIE, 2016, p. 330)38.

Los principios que inspiran la legislación francesa de protección, se relacionan, entonces, inevitablemente, con la materialización de determinados derechos fundamentales sobre los cuales además se sientan sus bases: igualdad, dignidad, desarrollo de la personalidad, entre otros; no obstante, no es posible subsumir los derechos fundamentales en un solo principio, ni viceversa; máxime cuando "principio" y "derecho fundamental" no significan lo mismo ${ }^{39}$.

\subsection{Principio de necesidad}

El campo de aplicación de los regímenes de protección en el sistema francés, viene dado precisamente por la "necesidad" (MALAURIE, 2016, p. 291). Tal necesidad dice relación con la alteración de las facultades de una persona. Ese es el criterio a partir del cual deben activarse los sistemas de protección: sólo si se ven afectadas

33 En este apartado no estudiaremos los principios que inspiran la Convención (ratificada por Francia con posterioridad a la Ley de 5 de marzo de 2007), sino de la legislación francesa de protección: del Ccf y de las demás normas afines, aunque muchos de ellos, como luego veremos, coinciden. Un estudio de los principios que inspiran la Convención y las recomendaciones realizadas por el Comité de Ministros del Consejo de Europa, puede verse en KJAERUM.

34 El orden, número y estructura de principios a tratar no está basado ni únicamente del texto de ley, ni de ninguna doctrina en particular.

35 Antes de la reforma de 2007.

36 Señala también el autor, y con mucha razón, que se trata de una novedad legal mas no jurídica, ya que la jurisprudencia venía afirmando ya desde el año 1989 que las medidas de protección no solo tenían por objeto los bienes, sino también la persona del, en ese entonces, incapaz; en el mismo sentido BAUDIS: el autor manifiesta que se trata de prácticas que ya había instaurado la jurisprudencia y que la ley de 2007 viene a consagrar dichas prácticas a través de una dimensión adaptada a las necesidades actuales de los mayores bajo protección. El Libro Blanco tiene por objeto sensibilizar a los poderes públicos sobre las mejoras que pueden realizarse en la puesta en marcha de la ley de 5 de marzo de 2007 .

37 Se denomina Juez de Tutelas al juez especializado en la adopción de medidas de protección. Se ventilan ante él todas las medidas y no únicamente, como pudiera pensarse, la tutela. Ha sido creado ya en el año 1964 y es una pieza clave de la protección tanto de mayores como de menores. El juez territorial competente es aquel que corresponda a la residencia habitual de la persona protegida. El Defensor de Derechos, se ha pronunciado ya sobre la pertinencia de renovar su denominación a la de "juez de protección de mayores”, noción que coincidiría de mejor manera con la amplitud de sus funciones. Como noción básica, entiéndase que el Defensor de Derechos (Défenseur de Droits) es designado por el Gobierno como un mecanismo independiente, encargado del seguimiento de la aplicación de la Convención relativa a los Derechos de Personas con Discapacidad. Se asegura, de este modo, la misión de acompañamiento de las personas con discapacidad en el conocimiento y la defensa de sus derechos. El Rapport, por su parte, es un análisis que se realiza para dar cuenta del estado en que se encuentra la aplicación de la Convención en Francia y se elabora a partir de los requerimientos de la población y los testimonios y audiciones de los actores en terreno quienes están en contacto cotidiano con las problemáticas abordadas en él.

38 Aprovechamos este apartado para explicar cómo se financia la puesta en marcha de las medidas de protección. En primer lugar incumbe a la colectividad pública, debido a la solidaridad nacional; una parte de los gastos son soportados por el mayor protegido, teniendo en cuenta el estado de sus recursos (a sus familias o a sus herederos).

39 Si vamos aún más lejos, podemos afirmar incluso que todos los principios, a su vez, se relacionan entre sí; no obstante, a efectos de conservar un esquema claro que permita una mayor comprensión del sistema, vamos a tratar cada uno de ellos por separado. 
las facultades de una persona, ésta debe ser protegida; en caso contrario, no se justifica la asunción de ninguna medida de protección (VOIRIN, 2016, p. 237) ${ }^{40}$.

Dispone el art. 425, inciso I del Ccf que toda persona que se encuentre en la imposibilidad de proteger por si misma sus intereses, debido a una alteración, médicamente constatada, ya de sus facultades mentales, ya de sus facultades físicas o corporales que impidan la expresión de su voluntad, puede beneficiarse de una medida de protección jurídica, de aquellas contenidas, dice el legislador, en el presente capítulo, (refiriéndose a los artículos siguientes). Es necesario que siempre que se abra una medida de protección esta tenga por respaldo un fundamento médico (CARBONNIER, 2017, p. 654)41. Esa constatación médica sólo puede ser otorgada por uno de los profesionales inscritos en la lista que confecciona el Procurador de la República para tales efectos.

Por tanto, cuando se habla del "principio de necesidad", significa que deben existir a lo menos dos condiciones básicas para la apertura de una medida de protección jurídica, ya establecidas en la ley de 1968 y conservadas por la ley de 2007, a saber: una alteración de las facultades de la persona, médicamente constatada; y la imposibilidad de autogobernarse (vale decir, de proteger por si misma sus intereses).

Es importante señalar sin embargo que, aun existiendo estos dos presupuestos, no se justifica la apertura de una medida cuando existe otro mecanismo de protección de los intereses de la persona afectada: como es, por ejemplo, la protección por parte de la familia o la ayuda de un tercero, o incluso un mandato de protección futura (MOLIN, 2017, p. 49-50)42. Por tanto, y como afirmación categórica y fundamental, no existe una automaticidad o consecuencia inmediata entre la existencia de una discapacidad y la puesta en marcha de una medida de protección, ya que únicamente se puede establecer un mecanismo, sea de apoyo o sustitución de voluntad, cuando se cumplan las condiciones establecidas por el legislador (PECQUEUR; CARÓN-DÉGLISE; VERHEYDE, 2016, p. 958)³.

\subsection{Principio de subsidiaridad ${ }^{44}$}

Enlazando con lo anteriormente dicho, creemos que hay dos aristas claras de la subsidiaridad, como base del sistema de protección de mayores con discapacidad. Por un lado, tenemos la subsidiaridad de la intervención del Estado, en sentido tal que esta sólo tendrá lugar cuando la familia no pueda hacerse cargo del mayor, o cuando no exista otro mecanismo ya establecido por el legislador de apoyo o de substitución de voluntad según sea el caso, en los que no se intervenga ni administrativa ni judicialmente (BAUDIS, 2012, p. 15)45. Además, sólo en caso de que ningún miembro de la familia o ningún cercano pueda asumir la tutela o la curatela, se designará un mandatario judicial de protección del mayor (véase lo dispuesto en los arts. 447- 450 1el Ccf). Por otro lado, la subsidiaridad opera también al interior del sistema de protección jurídica en sentido tal que se preferirán, siempre que sea posible, aquellas medidas que no signifiquen la restricción de la capacidad del protegido, ocupando la tutela el "último lugar de la lista" (CARBONNIER, 2017, p. 551-553, DEFENSEUR DE DROITS, 2016, p. 16)4. Esta segunda arista de la subsidiaridad se relaciona también con la proporcionalidad, según veremos a continuación.

40 Podría pensarse que este es un criterio que rige solo para las medidas de protección de carácter judicial. Sin embargo, por ejemplo, el mandato de protección futura (que es una medida de carácter voluntario) si bien no es concebido bajo un estado de necesidad de quien lo confiere, sí está destinado a surtir sus efectos únicamente cuando se vean alteradas las facultades de quien haya realizado dicha designación y, por tanto, un estado de necesidad futura. La figura del mandato de protección futura la veremos más adelante.

41 Sin embargo, y esto es importante de aclarar, no se condiciona el aspecto médico al aspecto civil, ni viceversa. El régimen civil y el tratamiento médico son independientes el uno del otro, pero el régimen civil sí puede estar influenciado por aspectos médicos u extra médicos. No creemos que sea negativo tomar en cuenta una opinión médica, como sí lo sería en cambio basar el sistema de protección únicamente en ella. Art.490-1 del Ccf.

42 Es aquí donde deben tenerse en cuenta, en primer lugar, las reglas de derecho común relativas a la representación; y, en segundo lugar, aquellas reglas relativas a los derechos y deberes de los cónyuges y a los regímenes matrimoniales. Véanse los artículos 217 y 219 del Ccf que permiten al juez de tutelas autorizar a uno de los cónyuges para la realización de un acto en concreto o para representar a su cónyuge de manera general. Véanse también los artículos 1426 y 1429 en los cuales se otorga la posibilidad a uno de los cónyuges de solicitar al tribunal la sustitución de la voluntad del otro. Lo que queremos advertir es que en el Ccf existen otros mecanismos que no significan necesariamente la apertura de una medida, a fin de proteger a quien se vea impedido de manifestar su voluntad. Esto se relaciona, por supuesto, con el principio de subsidiaridad.

43 Esta es una de las manifestaciones claras a partir de las cuales podemos señalar que el sistema francés se adecua, como afirmaremos posteriormente, a las exigencias de la Convención.

44 Podemos llamarle también principio de ultima ratio, pues a ello apunta efectivamente su contenido.

45 Se refuerza el rol de la familia, como indica el art. 415 del Ccf. Ya en el año 2010 en Francia, a nada de entrar en vigor la ley de 2007 un $47 \%$ de las tutelas y curatelas eran confiadas a las familias (familia cuya noción es también ampliada por la ley, teniendo en cuenta la evolución sociológica y la realidad de los lazos existentes actualmente entre los individuos).

46 Como es evidente, entonces, la incapacitación (privación judicial de la capacidad de obrar) es de carácter excepcional. El Defensor de Derechos considera que tal mecanismo no será sino aplicado de manera excepcional, solo para aquellos casos en los que una persona se encuentre en una situación de "incapacidad total" de manifestar su voluntad o sus preferencias y en caso de no poder accionar otra forma de acompañamiento o medida adaptada a sus necesidades. 


\subsection{Principio de proporcionalidad}

Cuando hablamos de proporcionalidad, hay que referirse a dos aspectos fundamentales que deben tenerse en cuenta a la hora de adoptar una medida de protección determinada: la graduación y la temporalidad (relacionado este último también con el seguimiento de la medida).

La graduación dice relación con la necesidad de individualizar la medida, según el estado, más o menos profundo, de alteración de las facultades de la persona protegida (GUILARTE MARTÍN-CALERO, 2016, p. 61, CARBONNIER, 2017, p. 547 y ss. ${ }^{47}$. El art. 428, inciso II del Ccf es lo suficientemente gráfico cuando señala que el juez es llamado a adaptar e individualizar la medida de protección en función del grado de alteración de las facultades personales del interesado. De este modo, y en palabras de MOLIN (2017, p. 51), el juez aún en los casos de tutela y curatela, debe "modular" la capacidad del protegido ${ }^{48}$.

En resumidas cuentas, no se trata de un sistema rígido de aplicación general, sino más bien de una aplicación casuística, previo estudio de las circunstancias personales del protegido. "Ha de existir una correspondencia razonable entre la capacidad natural de conocer y querer, y la intervención legal sobre las posibilidades de actuación en la vida jurídica.". Así, "...los principio de protección a las personas con discapacidad (...) y del libre desarrollo de la personalidad (...) se complementan y, a la vez, se limitan mutuamente, determinando el equilibrio que debe encontrar la regulación civil, de forma que no caiga en una protección tan exacerbada que ahogue las posibilidades de desarrollo de la personalidad, ni dé a éste tanta amplitud que acabe por establecer un régimen de protección marcadamente insuficiente en perjuicio del propio discapacitado psíquico" (MARTíNEZ DE AGUIRRE, 2014, p. 49-50, GUILARTE 2016, p. 61-62, 73 y ss.)49-50. En palabras de MALAURIE, si de una manera o de otra la protección es o insuficiente o excesiva, el incapaz sufrirá. La alteración de las facultades puede ser más o menos profunda y la incapacidad o falta de aptitud, por tanto, más o menos extendida (MALAURIE, 2016, p. 244)51.

Por su parte, y en cuanto a la temporalidad se refiere, la ley de 5 de marzo de 2007 fijaba un máximo de duración de las medidas de protección de 5 años, bajo pena de caducidad. Cumplido tal plazo, se procedía a la revisión de la medida y en caso de no ser renovada, expiraba automáticamente. Sin embargo, ante las dificultades prácticas del cumplimiento de tales plazos (dadas principalmente por la elevada carga de trabajo de los jueces de tutela) es que la ley de 16 de febrero de 2015 ( $N^{\circ}$ 2015-177), ha modificado (entre otras disposiciones) los arts. 441 y 442 del Ccf De este modo se ha aumentado el plazo máximo de la duración de las medidas a 10 años, siempre que sea debidamente justificada dicha duración; y se conserva la posibilidad de renovación, previendo eso sí una duración máxima de 20 años que antes no existía (DEFENSEUR DE DROIT, 2016, p. 37 y ss.).

\subsection{Respeto y promoción de la autonomía}

En palabras de NOGUERO (2016, p. 964), existe un movimiento a nivel internacional favorable a la autodeterminación del mayor vulnerable (GUILARTE 2016, p. 72) s2-53. $^{5}$

Se define la autonomía como la autodeterminación humana, la capacidad de obrar libremente. La pérdida de autonomía va de la mano de la pérdida de la capacidad jurídica (DENIZEAU, 2014, p. 138), mas no por ello

47 Y ello porque la discapacidad no es relevante en sí misma, sino solo si afecta la capacidad de autogobierno. En este sentido, véase, por ejemplo, GUILARTE MARTín- CALERO, Cristina quien señala que se pueden ordenar las discapacidades en dos grupos: aquellas que son más profundas y que solo podrían remediarse en términos jurídicos a través de una medida que implique la representación (tutela, por ejemplo), y aquellas que son menos graves, que son en realidad discapacidades intermedias y que pueden remediarse en cambio a través de una mera asistencia (como sería, por ejemplo, la curatela).

48 Podemos también citar en este sentido al art. 440, incisos II y IV del Ccf de los cuales se desprende que una medida como la tutela o la curatela (o incluso la habilitación familiar) no debe ser pronunciada si la salvaguarda judicial (medida sin ninguna intervención en los actos de la persona protegida) aparece como suficiente para la protección del mayor.

49 En la p. 64 la autora habla muy acertadamente de la "personalización de la medida de protección".

50 Ya es más que conocida aquella expresión del "traje a la medida" utilizada por la Sala Primera del Tribunal Supremo de España en la sentencia de 1 de julio de 2014: "se trata de un traje a medida que precisa de un conocimiento preciso de la situación en que se encuentra esa persona...".

51 El autor destaca además que durante mucho tiempo era la única causal de incapacidad la alienación mental y que se han ido incorporando otras causales, como por ejemplo, la vejez, especialmente cuando va acompañada de demencias seniles o de la enfermedad de Alzheimer (pp. 300 y 301).

52 Puede entenderse por autogobierno la "actitud necesaria para obrar por uno mismo, para actuar libremente...". Tanto la definición de autonomía, como la de dependencia, han sido extraídas de la Ley española 39/2006 de 14 de diciembre, de promoción de la autonomía personal y atención a las personas en situación de dependencia.

53 La Convención establece en su art. 3 el respeto a la autonomía individual, incluida la libertad de tomar las propias decisiones y la independencia de las personas. De otro tanto se ocupa el art. 12 de la misma Convención al que haremos alusión posteriormente. 
de la pérdida o alteración de la personalidad. La ley de 2007 establece como uno de sus pilares fundamentales la conservación de la capacidad jurídica, la actuación del mayor, y la prevalencia de su voluntad en la toma de decisiones; todas aristas del principio de respeto a la autonomía del protegido.

Se ha definido como la "capacidad de controlar, afrontar y tomar, por propia iniciativa, decisiones personales acerca de cómo vivir de acuerdo con las normas y preferencias propias así como de desarrollar las actividades básicas de la vida común". Por dependencia, en cambio, se entiende: "el estado de carácter permanente en que se encuentran las personas que, por razones derivadas de la edad, la enfermedad o la discapacidad, y ligadas a la falta o a la pérdida de autonomía física, mental, intelectual o sensorial, precisan de la atención de otra u otras personas o ayudas importantes para realizar actividades básicas de la vida diaria o, en el caso de las personas con discapacidad intelectual o enfermedad mental, de otros apoyos para su autonomía personal" (TRIBUNAL SUPREMO DE ESPAÑA, 2014).

El art. 458 del Ccf. dispone que los actos cuya naturaleza sea tal que impliquen un consentimiento estrictamente personal, no puedan tener lugar o celebrarse bajo asistencia o representación. A renglón seguido se establece un listado no taxativo de algunos actos reputados (legalmente) como personales: la declaración de nacimiento y el reconocimiento de un hijo; los actos de autoridad parental relativos a la persona del hijo; y el consentimiento dado para la propia adopción, entre otros (CORTE DE CASACIÓN FRANCESA, 2015).

Por su parte, el art. 459, inciso I del mismo Código se encarga de señalar que la persona protegida tomará por sí misma las decisiones relativas a su persona en proporción a cuanto la medida adoptada y su estado así lo permitan, de modo tal que no se aplica en principio la asistencia o la representación en aquellos actos, incluso cuando se ha adoptado una tutela, salvo que el juez haya expresamente previsto lo contrario, ya sea al momento de apertura de la medida o a través de un acto ulterior. Tanto el juez, como el consejo de familia, si estuviere constituido podrán ejercer la protección del mayor en actos relativos a su persona, si este no estuviere en estado de tomar decisiones por sí mismo (Art. 459, inciso II). Asimismo, y relacionado con el principio ya visto de la proporcionalidad, el juez deberá asegurarse en todo momento que las modalidades de la medida de protección adoptada sean adaptadas al estado de salud del mayor (art. 457, inciso I).

Finalmente, y con el objeto de garantizar la autonomía y el ejercicio de la libertad individual de la persona protegida, la ley de 5 de marzo de 2007 le confiere al mayor protegido el derecho general a ser informado de su situación personal, los actos realizados y su utilidad, los efectos y las consecuencias de su negativa a la realización de un acto determinado, etc. (art. 457, inciso I). Ese derecho, según veremos, es matizado o da lugar a excepciones en determinadas circunstancias (MOLIN, 2017, p. 51 y ss., TEYSSIE, 2016, p. 490 y ss., MALAURIE, 2016, p. 253 y ss., 338) $)^{54-55}$.

Aún con todo lo dicho, creemos que la conservación de la autonomía y la autodeterminación no puede ser un principio absoluto y ello porque precisamente las discapacidades de carácter intelectual pueden variar y distar mucho unas de otras. Sí creemos que, siempre que sea posible, debe promoverse la autonomía. También creemos que si no es posible aquella autonomía, la representación debe siempre velar por los intereses de la persona protegida e incorporarle ya sea a través de su opinión o de su historia de vida si no fuere posible que emita ningún tipo de manifestación corporal. ¿Cómo podría una persona en un coma profundo irreversible o aquella que se

54 Así, por ejemplo, el mandatario judicial de una persona protegida cuyo estado no le permita recibir dicha información, remitirá los antecedentes a uno de los miembros del Consejo de Familia, si este estuviere constituido o en su defecto a un pariente o allegado (art. L.471-8, inciso III, del Casf.). El Consejo de Familia es una figura complementaria a la tutela, que si bien no es obligatoria puede ser de gran utilidad. El artículo 456 del Ccf remarca el carácter subsidiario del Consejo de Familia y fija para su configuración y actuación dos requisitos fundamentales: Que las necesidades de protección de la persona o la consistencia de su patrimonio lo justifiquen; Que la composición de su familia y de su entorno así lo permitan. Es el juez de tutelas quien designa a los miembros del Consejo de Familia mientras dure la tutela, y se compone de a lo menos cuatro miembros, entre ellos el tutor y el tutor subrogante. No existe un número máximo de miembros y estos son designados teniendo en consideración lo expresado por la persona protegida, sus relaciones habituales, su interés y las eventuales recomendaciones de los parientes cercanos, como de su entorno. La composición del Consejo de familia es una de las facultades discrecionales del juez de tutelas. El Consejo puede funcionar con o sin él. Cuando funciona con el Juez de tutelas es convocado por éste según lo dispone el art. 1234 del Cpc. Cuando funciona sin él, tiene por objeto evitar cualquier abuso y su actuación está sujeta a dos condiciones: la autorización previa del juez de tutela, según dispone el art. 1237 del CPc; y la designación por parte del Consejo de un mandatario judicial para la protección del mayor en calidad de tutor o de tutor subrogante.

55 Existen normas específicas relativas a la decisión de someterse o no a un tratamiento médico determinado (o de poner fin a aquel que se esté llevando a cabo) para aquellas personas mayores que se encuentran bajo medida de protección, y la manera en que estas pueden expresar su voluntad. Véase en tal sentido el Code de la Santé Publique, arts. L. 1110-5; L.111-6; L.111-11; y L.111-12, introducidos por la ley N²016-87 de 2 de febrero de 2016. También existen disposiciones especiales que regulan la posibilidad de contraer matrimonio o firmar un pacto de unión civil por parte del mayor protegido, cuestión en la que no entraremos en esta ocasión. Quien desee consultar el Ccf, debe dirigirse a los arts. 460 al 462. 
encuentra en una fase final de una enfermedad neurodegenerativa expresar su voluntad? (NOGUERO, 2016, p. 966). Ello es impensable y por tanto debe sustituirse su voluntad a través de un mecanismo de protección que implique, necesariamente su representación (y por ende, la pérdida de autonomía). Por tanto, para determinar el nivel de autonomía del que debe o puede gozar una persona con discapacidad se debe estar a su real estado de salud y entendimiento. De ahí que la clave es la proporcionalidad: a mayor alteración de las facultades mentales, menor autonomía y viceversa. Creemos que el derecho francés cumple con ese matiz, aún cuando el Comité haya observado su legislación ${ }^{56}$. La autonomía supone una voluntad lúcida y no puede existir una autonomía sin límites porque ello sería más bien pernicioso.

\subsection{Interés del mayor protegido}

Como ya anunciábamos, este es un asunto controvertido y que se discute acaloradamente en las sesiones de seminarios, congresos o conversatorios referidos a la capacidad de las personas con discapacidad y el enfrentamiento de su autonomía con su mejor interés.

El art. 415 del Ccf. en su inciso III señala que las medidas establecidas por el legislador tendrán por finalidad el "interés de la persona protegida". De tal redacción, como señala PECQUEUR et alii (2016, p. 960), podría suponerse que habría un interés objetivo, único y superior que el juez de tutelas y la persona encargada de llevar a cabo la medida de protección deben respetar. No obstante, creemos que no es ese el espíritu del legislador, y dicho interés debe entenderse únicamente como la obligación de "tomar el menor riesgo posible" en la ejecución de las medidas. La noción del interés del mayor protegido no es única y, por tanto habría de hablarse de intereses en plural. Tales intereses deberán ser determinados observando de manera óptima sus necesidades esenciales y sus opciones de vida y hábitos actuales. Sin embargo, no parece razonable pensar que se aquel interés se basará en las voluntades y preferencias de la persona que se pretende proteger porque si no tiene las aptitudes suficientes para manifestar su voluntad, no podría entonces la decisión judicial acogerse a algo que no existe. Por su parte, no siempre lo que se quiere (y eso con o sin discapacidad) es lo mejor; y sí, cada quien asume ese riesgo, es verdad, pero cuando estamos frente a personas que tienen una discapacidad tal que sus facultades se encuentran alteradas al punto de no generar un proceso adecuado de decisión, entonces no podemos hacerles responsables por aquellas decisiones; y si no pueden responder, entonces tampoco pueden decidir: es necesario que otro decida y, como garantía, que ese otro responda si la decisión es injusta, arbitraria, o no se basa en las necesidades reales de la persona protegida.

Dicho lo anterior, creemos que existen básicamente dos manifestaciones claras del respeto del interés del mayor protegido (aunque quizás todos los principios estudiados apunten en el mismo sentido ${ }^{57}$, razón por la cual lo hemos dejado para el final). Nos referimos al derecho a ser oído y al principio contradictorio imperante en los procesos de apertura de medidas de protección.

Los artículos 432 y 494.4 del Ccf imponen al juez de tutela la obligación de oír al mayor antes de instaurar una medida de protección, o cuanto menos la obligación de citarle a ser oído. Las condiciones bajo las cuales debe realizarse dicha audición están contempladas en los arts. 1120 y 1121.1 del Cpc. Entre algunas de sus particularidades podemos mencionar: la posibilidad de contar con el apoyo de un profesional médico, si el juez así lo estima pertinente; la no publicidad de la audición y los diferentes lugares en que esta puede ser llevada a cabo (residencia habitual de la persona a proteger, centro residencial, hospital o despacho del tribunal, según sea el caso) (MOLIN, 2017, p. 61 y ss.). Sin embargo, cabe señalar que el juez de tutelas, a través de una decisión especialmente motivada y bajo la advertencia de un médico inscrito en la lista del procurador de la República (y de carácter muy excepcional) puede determinar que no habrá lugar a la audición del interesado en los casos siguientes: si la audición pudiere significar un perjuicio para la salud del mayor; si el mayor se encontrare en condición tal de salud que se vea impedido de manifestar su voluntad. Nos parece que aquellos resguardos que toma el legislador van precisamente en la línea de la protección y de no exponer a las consecuencias de una decisión a quien no se encuentra en condiciones de tomarla por sí solo. Lo contrario sería una desprotección, e iría en contra de lo que impone el mismo art. 12 de la Convención en su inciso III. Es verdad que en aquellos casos debe salvaguardarse aún más al sujeto protegido y que deben establecerse garantías a su favor: ello se cumpliría con la obligación de

\footnotetext{
Sobre las observaciones realizadas básicamente a la figura de la tutela, nos referiremos en un apartado posterior.

Primordialmente el principio de respeto y promoción de la autonomía del mayor.
} 
justificar la medida y con la posterior rendición de cuentas, o un sistema adecuado de responsabilidad al que se verá obligado quien actúe en lugar y nombre de la persona protegida.

Por su parte, el decreto $\mathrm{N}^{\circ} 2008-1276$ de 5 de diciembre de 2008, recuerda de una manera general la importancia del principio contradictorio para todas las decisiones y medidas que adopte el juez de tutelas y regula el procedimiento aplicable (al que no nos referiremos especialmente en este momento). También podemos mencionar el decreto N.2016-185 de febrero del mismo año en el que se regula lo relativo a la habilitación familiar. Estas reglas reemplazaron el capítulo X, del Título I, del Libro III del Cpc. Se trata de artículos aplicables no sólo para la apertura de las medidas, sino también para la renovación de estas, si procediere, salvas determinadas excepciones que veremos en su momento.

Según el art. 432 del Ccf la persona a proteger puede ser acompañada, durante la audición, por un abogado o, bajo reserva y estando de acuerdo el juez, por otra persona de su elección. Esta norma es complementada por el art. 1214 del Cpc en el que se prevé que en todas las instancias relativas a la apertura de una medida de protección, su modificación o su levantamiento, el mayor a proteger o la persona protegida, en su caso, puede elegir un abogado o bien solicitar que se le designe uno de oficio y a que los interesados sean informados de sus derechos en el acto de la convocatoria (DEFENSEUR DE DROITS, 2016, p. 27) s8. $^{\text {s }}$

\subsection{Principio de igualdad}

El Código de la Acción Social y de las Familias en su art. L. 114-1 establece que toda persona con discapacidad tiene derecho a la solidaridad del conjunto de la colectividad nacional que le garantiza, en virtud de tal obligación, el acceso a los derechos fundamentales reconocidos a todos los ciudadanos, así como el pleno ejercicio de su ciudadanía. El inciso II del mismo art. señala que el Estado garantiza la igualdad de tratamiento de las personas con discapacidad sobre todo el territorio, definiendo los objetivos plurianuales de acción.

Creemos, sin embargo, que aquellas situaciones que no son de carácter ordinario, no pueden ser tratadas de manera común y, por tanto, un tratamiento diferenciado estaría justificado precisamente en la situación especial en la que se encuentra una persona vulnerable (en este caso, una persona con discapacidad en tanto se vean afectadas sus capacidades volitivas y la toma de decisiones), sin que sea razonable entonces denunciar un atentado contra la igualdad o una discriminación en sentido estricto derivado de la asunción de medidas orientadas a su protección ${ }^{59}$. El respeto a la diferencia no significa ni puede significar un desconocimiento a la misma. No se puede actuar como

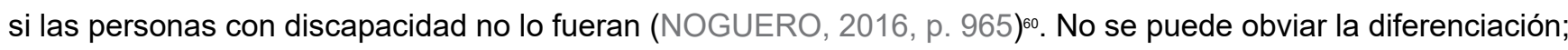
más aún, obviarla significaría una desprotección en desmedro de quienes no pueden autogobernarse.

\section{5 ¿Es compatible la legislación francesa con el art. 12 de la Convención de las Naciones Unidas de los Derechos de Personas con Discapacidad?}

Francia ha ratificado la Convención de las Naciones Unidas de los Derechos de las Personas con Discapacidad el 18 de febrero de 2010 a través de la ley № 2009-1701 de 31 de diciembre de 2009, comprometiéndose a tomar todas las medidas adecuadas a fin de modificar o derogar tanto las disposiciones legales y reglamentarias, como las prácticas que signifiquen fuente de discriminación en relación a las personas protegidas o por proteger y de garantizar la puesta en escena de sus derechos fundamentales (MARTíNEZ, 2016. p. 590) ${ }^{61}$.

La Convención enuncia un vasto conjunto de derechos económicos y sociales para las personas con discapacidad sobre la base de la igualdad y no discriminación con los demás, y las obligaciones que en ella se imponen buscan garantizarles el goce efectivo de tales derechos. La persona con discapacidad es definida por

58 En tal sentido, el Defensor de Derechos ha advertido que, teniendo en consideración los efectos que puede acarrear una medida de protección, sería óptimo que la audiencia del mayor se haga siempre en presencia de un abogado, a fin de que éste asuma su representación en juicio, si fuere necesario, o que ejerza una asistencia a lo largo de todo el procedimiento.

59 Téngase en cuenta aquí también el concepto de discriminación por razón de discapacidad que otorga el art. $2^{\circ}$ de la Convención.

60 Es necesario admitir, señala el autor, que cada uno de nosotros (refiriéndose a quienes no sufren de discapacidad) también perdemos aptitudes en determinadas circunstancias y también perdemos oportunidades para realizar algunos actos en otras; y ello no significa, en ninguno de los casos, una ruptura de la igualdad.

61 Es importante tener en consideración que el Tribunal Europeo de Derechos Humanos viene señalando que la Convención es un mecanismo de interpretación general, aún para aquellos países que no la hubieren ratificado. 
el art. 1, inciso II como: “...aquellas que tengan deficiencias físicas, mentales, intelectuales o sensoriales a largo plazo que, al interactuar con diversas barreras, puedan impedir su participación plena y efectiva en la sociedad, en igualdad de condiciones con las demás" (BLATMAN, 2016, p. 169) ${ }^{62}$.

Si bien es cierto que todas las discapacidades deben interesarle o le interesan efectivamente al Derecho, las únicas que realmente determinan la necesidad de disponer de mecanismos de protección que impliquen un sistema de apoyo o de sustitución de capacidad, son las alteraciones que afectan la posibilidad de manifestar libre y claramente la voluntad, vale decir las alteraciones de carácter psíquico o mental (MARTÍNEZ DE AGUIRRE, 2014, 35-36)

El art. 12 de la Convención afirma un principio de igualdad en el reconocimiento de la personalidad y de la capacidad jurídica de las personas con discapacidad, abordando la cuestión de la capacidad jurídica desde la perspectiva de los derechos humanos ${ }^{\varsigma 4}$. El denominado "modelo social" aporta una visión basada en los derechos fundamentales que supone la comprensión de que todas las personas, incluidas aquellas que sufren de discapacidad, son sujetos de derechos y no simples objetos de políticas asistenciales. Y "No se trata, en este sentido, de hacer que las personas con discapacidad tengan derechos específicos por ser diferentes (proceso de especificación), sino simplemente de que disfruten de los mismos derechos que el resto de las personas en igualdad de condiciones (proceso de generalización)" (BARRANCO et all.,, 2012, p. 56).

El reconocimiento de la capacidad jurídica es, sin duda, imprescindible para que las personas con discapacidad puedan actuar efectivamente en la sociedad. Por tanto, no basta con que sean titulares de derechos sino también que puedan ejercerlos. Sin embargo, y tal como hemos afirmado, no parece que este principio sea de tal manera absoluto que impida que, en determinadas circunstancias, se emplee el mecanismo de la representación (MARTíNEZ PÉREZ, 2016, p. 584).

Es el mismo Comité el que luz de los principios generales enunciados en el art. 3 de la Convención, el Comité de Derechos de la Organización de las Naciones Unidas para la puesta en marcha de la Convención en Francia ${ }^{65}$, en su Observación General N ${ }^{\circ} 1$ (de mayo de 2014) (6) $^{6}$ reafirma que el hecho de que una persona tenga una discapacidad, no es justificante para que sea privada de su capacidad jurídica ni, por consecuencia, de ninguno de los derechos previstos en la Convención (DEFENSEUR DE DROIT, 2016, p. 9).

Sin embargo, existe una tendencia internacional que estima que cualquier régimen de protección jurídica de las personas mayores con discapacidad que limite su capacidad jurídica es, por ese solo hecho, contrario al art. 12 de la Convención. Así, la tutela, como régimen de representación y, por tanto sustitutivo de voluntad, es

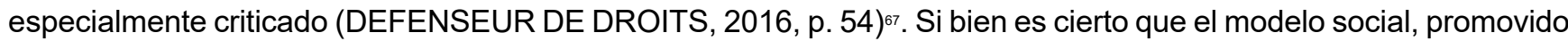

62 Artículo trascrito de la versión de la Convención en español. Ha sido juzgada como una definición extensa que parece más una "no definición".

63 "Efectivamente el problema de una persona con discapacidad física, o en la inmensa mayoría de los casos, de un discapacitado puramente sensorial, no es el de tomar decisiones libre y consciente...". El autor ejemplifica refiriéndose al caso de un ciego o de una persona en silla de ruedas. Es cierto que en ambos supuestos, el Derecho se ocupa de proporcionar mecanismos que significarán, finalmente, la actuación por sí mismos y no apoyados o representados por otro. En el primer caso, al escribir en sistema Braille, por ejemplo, no se lee en lugar del ciego sino que es éste quien lee por sí mismo; en el caso de quien se mueve en silla de ruedas, la instalación de una rampla lo habilita para acceder por si solo, por ejemplo, al transporte público y no hace falta que otra persona lo haga por él. En el caso de las personas con discapacidades psíquicas el asunto es completamente distinto y, como ya se ha dicho, en algunas ocasiones debe restringirse o anularse su capacidad de obrar, precisamente para su protección.

64 "Los Estados Parte reafirman que las personas con discapacidad tienen derecho en todas partes al reconocimiento de su personalidad jurídica. 2. Los Estados Partes reconocerán que las personas con discapacidad tienen capacidad jurídica en igualdad de condiciones con las demás en todos los aspectos de la vida. 3. Los Estados Partes adoptarán las medidas pertinentes para proporcionar acceso a las personas con discapacidad al apoyo que puedan necesitar en el ejercicio de su capacidad jurídica. 4. Los Estados Partes asegurarán que en todas las medidas relativas al ejercicio de la capacidad jurídica se proporcionen salvaguardias adecuadas y efectivas para impedir los abusos de conformidad con el derecho internacional en materia de derechos humanos. Esas salvaguardias asegurarán que las medidas relativas al ejercicio de la capacidad jurídica respeten los derechos, la voluntad y las preferencias de la persona, que no haya conflicto de intereses ni influencia indebida, que sean proporcionales y adaptadas a las circunstancias de la persona, que se apliquen en el plazo más corto posible y que estén sujetas a exámenes periódicos por parte de una autoridad o un órgano judicial competente, independiente e imparcial. Las salvaguardias serán proporcionales al grado en que dichas medidas afecten a los derechos e intereses de las personas. 5. Sin perjuicio de lo dispuesto en el presente artículo, los Estados Partes tomarán todas las medidas que sean pertinentes y efectivas para garantizar el derecho de las personas con discapacidad, en igualdad de condiciones con las demás, a ser propietarias y heredar bienes, controlar sus propios asuntos económicos y tener acceso en igualdad de condiciones a préstamos bancarios, hipotecas y otras modalidades de crédito financiero, y velarán por que las personas con discapacidad no sean privadas de sus bienes de manera arbitraria”.

65 El Estado francés ha decidido en julio de 2011 otorgar a su comité la función de mecanismo independiente en atención a lo dispuesto en el art. 33 de la misma Convención.

66 Observaciones disponibles en http://www.convenciondiscapacidad.es/wp-content/uploads/2019/01/Observaci\%C3\%B3n-1-Art\%C3\%ADculo-12Capacidad-jur\%C3\%ADdica.pdf [última visita, 05 de noviembre de 2021].

67 Señala: La tutela, en tanto que mecanismos de decisión sustitutiva de la voluntad del protegido es contraria a la Convención y atenta contra la capacidad jurídica del mayor protegido y debe, por tanto, ser tomada como un régimen de excepción, destinada únicamente a aquellos casos en que la persona se ve absolutamente imposibilitada de manifestar su voluntad (parafraseo). 
por la Convención se decanta por la autonomía siempre que sea posible, no creemos que sea ese el espíritu del legislador internacional, porque hay circunstancias en la que la discapacidad es de tal intensidad que las personas afectadas no podrán, ni aún con apoyo, tomar determinaciones por sí mismos, de modo tal que la tutela (o cualquier otro sistema que signifique representación) no puede ser reemplazada por mecanismos de acompañamiento.

El Comité, señala que para que pueda respetarse la plena capacidad de las personas con discapacidad, en igualdad y sin discriminación, deben ser abolidos los sistemas de sustitución como la tutela, la curatela y las leyes relativas a la salud mental que permiten los tratamientos forzados, visión que en sí misma creemos que pudiera resultar extremista (NOGUERO, 2016, p. 964-965, PECQUEUR, et all. 2016, 958-959, MARTÍNEZ DE AGUIRRE, 2014, p. 25, BLATMAN, 2016, p. 264). Permitir a las personas con discapacidades psíquicas o intelectuales la participación plena y efectiva en la vida jurídica a todo evento, o bien sería impracticable o traería consigo graves consecuencias (MARTÍNEZ DE AGUIRRE, 2014, 48). Creemos que la supresión pura y simple de toda forma de representación podría atentar contra la protección de los mayores vulnerables. No puede abolirse simple y llanamente un sistema de representación, ni puede tampoco ser considerado este en sí mismo como obsoleto o atentatorio contra la integridad de las personas (MOLINA TOLEDO; ASTORGA GATJENS; GÓMEZ MOTTA, 2012, p. 74). Es una realidad: existen personas que no pueden gobernarse por sí mismas y que requiere de una protección contra los abusos y las consecuencias de las malas decisiones que puedan tomar (KJAERUM, 2016, p. 10, SCHULZE, 2010, p. 76 y ss.) ${ }^{68}$. Eso sí, y allí coincidimos plenamente con las expresiones contrarias a la representación, debe tratarse de situaciones excepcionales, en las que intervenga la autoridad judicial, en las que opere un adecuado sistema de revisión, y en el que, además, quien actúe en representación de la persona con discapacidad deba (para determinados actos) solicitar autorización ya sea a la justicia o a la administración.

En atención a lo dicho, creemos que el Estado francés sí cumple con la implementación del artículo 12 de la Convención a su Ordenamiento jurídico. El derecho francés de protección de mayores, en palabras de PECQUEUR et alii, está fundado sobre la base de los principios de necesidad, subsidiaridad y proporcionalidad de la medida y, lo que unido al principio de revisión regular de los mecanismos de protección adoptados, tal como lo define el art. 442 y ss. del Ccf, avalan tal afirmación (NOGUERO, 2016, p. 965, DEFENSEUR DE DROITS, 2016,

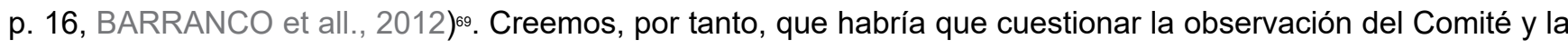
interpretación del art. 12 en sentido tal de abolir todo sistema de sustitución de voluntad ya que ello implicaría, como ya hemos afirmado, no sólo problemas prácticos, sino también una desprotección. Sin embargo, el sólo hecho de la limitación de la capacidad jurídica no significa la muerte civil de la persona protegida. Sí debe primar el sistema de apoyo, siempre que sea posible, frente a un sistema de sustitución (subsidiaridad, proporcionalidad).

Creemos que el sistema francés tiene por objeto el interés de la persona protegida y favorece, en la medida de lo posible, su autonomía. La ya expuesta ley № 2007-308 de 5 de marzo ha consagrado la protección de la persona y de los bienes de los mayores vulnerables, sometidos a un régimen de protección que es de carácter facultativo, ya sea judicial o convencional y que respeta, y así lo declara el art. 415 del Ccf las libertades individuales, los derechos fundamentales y la dignidad de la persona.

\section{Reflexiones finales}

La cuestión del respeto de la capacidad jurídica de las personas con discapacidad constituye un particular desafío para los Estados que han ratificado la Convención, significando, o debiendo significar, un esfuerzo que implique la armonización de sus normas internas a las exigencias del tratado internacional.

No basta con la prohibición de celebrar actos y contratos sino que se trata de encontrar un mecanismo adecuado que signifique la protección de la persona y los bienes de aquellos que, por cualquier motivo, requieran de otro para actuar en la vida del derecho.

68 Además, señala el informe que buena parte de los estados europeos contienen en sus legislaciones mecanismos que restringen o privan la capacidad jurídica del protegido (pp. 40 y ss.). Allí, además, aparece claramente que los fundamentos que se esgrimen para la no abolición absoluta de un sistema de sustitución vienen dados por los casos extremos en los que indudablemente se requiere de representación.

69 En este mismo sentido se manifiesta Noguéro cuando señala que se suscribe a la opinión de los jueces en sentido tal de defender que privar a una persona vulnerable de todo mecanismo de sustitución de capacidad, únicamente por una lucha contra la "discriminación", se puede tornar en contra de las personas que requieren una debida protección. 
Es importante distinguir entre la noción de personalidad jurídica y capacidad de obrar o de ejercicio. Si bien la personalidad jurídica no puede sufrir ningún tipo de limitación (porque implica la capacidad de goce), la capacidad de ejercicio puede verse y debe en ciertos casos limitarse de manera razonable y objetiva (BLATMAN, 2016, p. 265, MOLINA, 2012, p. 2677 ${ }^{7}$. La sola limitación en aras de la protección no puede considerarse per sé una discriminación.

Aquellas limitaciones deben responder a situaciones excepcionales y siempre operar de manera subsidiaria. Deben prevalecer los sistemas de apoyo frente a los de sustitución siempre que sea posible y basten como protección. Como señala MARTíNEZ DE AGUIRRE, desde cierto punto de vista la incapacitación (entendiendo por tal, la privación de la capacidad de obrar) es hasta beneficiosa para la persona con discapacidad quien, de no ser sustituido en su manifestación de voluntad (que, por cierto, no está en condiciones de otorgar), no podría ejercer por sí solo los derechos de que es titular.

La representación, cualquiera sea el nombre que se le atribuya, es un mecanismo razonable cuando como consecuencia de la discapacidad intelectual o mental, la capacidad natural de conocer y querer de una persona es casi inexistente.

Una postura como la que ha desarrollado el Comité en su observación General podría conducir, como ya se ha dicho, a la ausencia de toda medida de protección para aquellas personas que se hallan verdaderamente en la imposibilidad de autogobernarse ya que en aquellos casos toda forma de acompañamiento resultaría insuficiente e ilusoria.

Creemos que Francia respeta en sus normas los principios que sienta la Convención, a través de la diversificación de figuras que permiten la proporcionalidad y graduación de la protección, ubicando a la tutela y por tanto la representación en una posición subsidiaria frente al modelo de acompañamiento o de asistencia.

Es evidente que, como en todo sistema, hay cuestiones que en la práctica deben aún evolucionar, como es por ejemplo la comprensión popular y a veces judicial de la subsidiaridad como la abstención o rechazo a la protección judicial; o la exigencia por parte de determinados organismos público de una medida de protección como requisito para trámites tales como la obtención de ciertas prestaciones; o los problemas prácticos que presenta la figura de la curatela reforzada; los plazos de respuesta de los jueces, la falta de presupuesto de las familias para asumir de forma interna la protección del mayor, la aún escasa utilización del mandato de protección futura, la falta de adecuación de las normas del Ccf con las del Código de Salud Pública, y otras (BAUDIS, 2012, p. 30, DEFENSEUR DE DROITS, 2016, p. 56) ${ }^{71}$.

Chile necesita con urgencia una reforma (o más bien la creación) de un sistema de guardas que respete los parámetros establecidos en la Convención, que se base en el respeto de los derechos humanos y que signifique no un modelo médico sino social; pero que no implique una visión absolutista del artículo 12 de la Convención basado únicamente en los derechos humanos, sino es concordancia con los principios básicos del derecho civil: autonomía, responsabilidad, certeza jurídica, entre otros.

Es importante, finalmente, comprender y tener en cuenta que las dificultades prácticas que pudieran existir, no serán resueltas, ni en Francia ni en ningún otro país, por un cambio ni puramente de nomenclatura ni de legislación sino por la evolución de las prácticas que se realizan por parte de los organismos involucrados y el perfeccionamiento de sus actuaciones, de modo de acercar cuanto más sea posible la práctica a la letra de la ley.

\section{Referencias}

BARRANCO, M.; CUENCA, P.; RAMIRO, M. A. Capacidad jurídica y discapacidad: el artículo 12 de la Convención de Derechos de las Personas con Discapacidad. Anuario Facultad de Derecho, Alcalá de Henares, n. 5, p. 53-80, 2012.

BAUDIS, D. Préface. In: LIVRE Blanc: sur la protection juridique des majeurs. Paris: Convention Nationale des Associations de Protection de l'Enfant, 2012. p. 4-5. Disponible en: http://www.google.cl/url?sa=t\&rct=j\&q=\&esr $\mathrm{c}=\mathrm{s} \&$ source=web\&cd=3\&ved=0ahUKEwil34ns1/3TAhVHRhQKHV5HBigQFggqMAI\&url=http\%3A\%2F\%2Fwww.

70 Sin embargo, la Convención confunde los conceptos. Lo hacen también algunos autores, como por ejemplo, MoLıNA, cuando señala que el desconocimiento de la "capacidad jurídica" se traduce en la negación del derecho de la "personalidad jurídica".

71 Los propios usuarios denuncian que la puesta en marcha del sistema de protección de mayores no es plenamente efectiva y que existen ciertas disfunciones que subsisten. Denuncias puestas en evidencia por Baudis en el "Libro Blanco". 
unaf.fr\%2FIMG\%2Fpdf\%2Flivre_blanc_bd2.pdf\&usg=AFQjCNFC6s3bXK8k6tOHuyPPB66tJjjjPA\&bvm=bv.15142 6398,d.d24. Consultado el: 11 nov. 2021.

BESSON, S. La vulnérabilité et la structure des droits de l'homme: l'exemple de la jurisprudence de la cour européenne des droits de l'homme. In: BURGORGUE LARSEN, L. (dir.). La vulnérabilité saisie par les juges en Europe. Paris: Ediciones Pedone, 2014. p. 59-85.

BLATMAN, M. L'effet direct des stipulations de la Convention Internationale relative aux droits des personnes handicapées: rapport au Défenseur des Droits. Paris: Defenseur des Droits, 2016. Disponible en: http://www.defenseurdesdroits.fr/fr/publications/rapports/rapports-thematiques/rapport-blatman. Consultado el: 11 nov. 2021.

BURGORGUE LARSEN, L. La vulnérabilité saisie par les juges en Europe. Paris: Ediciones Pedone, 2014.

CARBONNIER, J. Droit civil: les personnes. 27. ed. Paris: Éditorial Thémis, 2017. t. 1. (Droit Privé).

CARON-DÉGLISE, A. Recueillir l'accord des personnes: du droit à la pratique. In: RENCONTRES

SCIENTIFIQUES DE LA CNSA POUR L'AUTONOMIE:autonomie et qualité de vie: entre pratiques et aspirations, 4., 2016, Paris. Dossier du participant [...]. Paris: Caisse nationale de solidarité pour l'autonomie, 2016, p. 92-

93. Disponible en: https://www.cnsa.fr/documentation/cnsa-rencontres_scientifiques-bdef.pdf. Consultado el: 11 nov. 2021.

CHILE. Código civil chileno. Santiago: Congreso Nacional de Chile, 1857. Disponible en: https://www.bcn.cl/ leychile/navegar?idNorma=172986. Consultado el: 22 enero 2022.

CHILE. Ley $\mathbf{N}^{\circ} \mathbf{1 8 . 6 0 0}$, de 30 de enero de 1987. Establece normas sobre deficientes mentales. Santiago: Presidencia da República, 2018. Disponible en: https://www.bcn.cl/leychile/navegar?idNorma=29991. Consultado el: 22 enero 2022.

CHILE. Ley $\mathbf{N}^{\circ} \mathbf{1 9 . 9 5 4}$, de 01 de julio de 2004. Modifica la ley 18.600, en lo relativo al procedimiento de interdicción de los discapacitados mentales. Santiago: Presidencia da República, 2004. Disponible en: https:// www.bcn.cl/leychile/navegar?idNorma=227545. Consultado el: 22 enero 2022.

DENIZEAU, C. La vulnerabilité dans la jurisprudence de la France et du Royaume-Uni. In: BURGORGUE LARSEN, L. (dir.). La vulnérabilité saisie par les juges en Europe. Paris: Ediciones Pedone, 2014. p. 117150.

DUBOUT, E. La vulnérabilité saisie par la cour de justice de l'union européenne. In: BURGORGUE LARSEN, L. (dir.). La vulnérabilité saisie par les juges en Europe. Paris: Ediciones Pedone, 2014. p. 31- 57.

ESPAÑA. Tribunal Supremo de España. STS 341/2014, de 1 de julio de 2014. Estima el recurso de casación contra Sentencia de Audiencia Provincial de Murcia, seccion 4 (civil), 29 de março de 2012. Magistrado responsável: Ignacio Sancho Gargallo, 1 de julio de 2014. Disponible en: https://supremo.vlex.es/vid/523367902. Consultado el: 11 nov. 2021.

ELÓSEGUI SOTOS, A. Experiencia práctica en la aplicación de las figuras de guarda legal. In: DE SALAS MURILLO, S. (coord.). Hacia una visión global de los mecanismos jurídico privados de la protección en materia de discapacidad. Zaragoza: El Justicia de Aragón, 2010. p. 245-256.

ESTUPIÑAN-SILVA, R. La vulnérabilité dans la jurisprudence de la Cour Inter Américaine de droits de l'homme: esquisse d'une typologie. In: BURGORGUE LARSEN, L. (dir.). La vulnérabilité saisie par les juges en Europe. Paris: Ediciones Pedone, 2014. p. 89-113.

EUROPEAN UNION AGENCY FOR FUNDAMENTAL RIGHTS. La capacité juridique des personnes souffrant de troubles mentaux et des personnes handicapées intellectuelles: estudio de la FRA (European Union Agency for Fundamental Rights). Vienna: FRA, 2016. Disponible en: https://fra.europa.eu/sites/default/ files/fra-2013-legal-capacity-intellectual-disabilities-mental-health-problems_fr.pdf. Consultado el: 11 nov. 2021. 
FRANCIA. Code Civil Français 1804. Paris: L'Imprimerie de la République, 1804. Disponible en: https://www. legifrance.gouv.fr/codes/texte_Ic/LEGITEXT000006070721/1804-03-29. Consultado el: 22 enero 2022.

FRANCIA. Code de la Santé Publique (CSP). Código de Sanidad Pública, 1953. Paris: République Française, [2022]. Disponible en: https://www.legifrance.gouv.fr/codes/texte_Ic/LEGITEXT000006072665/. Consultado el: 22 enero 2022.

FRANCIA. Code de l'Aide Sociale et des Familles (CASF). Código de Ayuda Social y de las Familias, 1956. Paris: République Française, [2022]. Disponible en: https://www.legifrance.gouv.fr/codes/id/ LEGITEXT000006074069/. Consultado el: 22 enero 2022.

FRANCIA. Code de Procédure Civil (CPc). Código de Procedimiento Civil, 2007. Paris: République Française, [2022]. Disponible en: https://www.legifrance.gouv.fr/codes/texte_Ic/LEGITEXT000006070716/. Consultado el: 22 enero 2022.

FRANCIA. Loi № 2007-308, du 5 mars 2007. Portant réforme de la protection juridique des majeurs. Paris: Présidence de la République, 2007. Disponible en: https://www.legifrance.gouv.fr/jorf/id/ JORFTEXT000000430707/. Consultado el: 22 enero 2022.

FRANCIA. Corte de Casación francesa. Sentencia de la Sala Civil n. ${ }^{\circ}$ 12-23-776, de 6 de noviembre de 2013. Impugnación a la decisión del Tribunal de Apelación de Colmar. Relator: Madame Guyon-Renard, 6 de noviembre de 2013. Disponible en: https://www.legifrance.gouv.fr/juri/id/JURITEXT000028175011. Consultado el: 11 nov. 2021.

FRANCIA. Loi № 2015-177, du 2 février 2015. Relative á la modernisation et á la simplification du droit et des procédures dans les domaines de la justice et des affaires intérieures. Paris: Présidence de la République, [2022]. Disponible en: https://www.legifrance.gouv.fr/loda/id/JORFTEXT000030248562/. Consultado el: 22 enero 2022.

FRANCIA. Défenseur des Droits. Rapport: Protection juridique des majeurs vulnérables. Paris: Défenseur des Droits, sept. 2016. Disponible en: http://www.google.cl/url?sa=t\&rct=j\&q=\&esrc=s\&source=web\&cd=1\&ved=0ah UKEwj_Lz6s5zTAhXD1RQKHSuiAKwQFggZMAA\&url=http\%3A\%2F\%2Fwww.defenseurdesdroits.fr\%2Fsites\% 2Fdefault\%2Ffiles\%2Fatoms\%2Ffiles\%2Frapport-majeurs_vulnerables-v5-num.pdf\&usg=AFQjCNH6FpM5HPsr m99eTJBU4ZA5Vh0waQ. Consultado el: 12 nov. 2021.

FRANCIA. Loi $\mathbf{N}^{\circ}$ 2016-87, du 2 février 2016. Créant de nouveaux droits en faveur des malades et des personnes en fin de vie. Paris: Présidence de la République, [2022]. Disponible en: https://www.legifrance.gouv. fr/loda/id/JORFTEXT000031970253/. Consultado el: 22 enero 2022.

FRANCIA. Loi N 2016-1547, du 18 novembre 2016. Modernisation de la justice du XXle siécle. Paris: Présidence de la République, [2022]. Disponible en: https://www.legifrance.gouv.fr/loda/id/ JORFTEXT000033418805/. Consultado el: 22 enero 2022.

FRANCIA. Convention International relative aux droits des personnes handicapées: Rapport Initial du Gouvernement Français. Paris: Gouvernement Français, 2016. Disponible en: http://www.google.cl/ url?sa=t\&rct=j\&q=\&esrc=s\&source=web\&cd=1\&ved=0ahUKEwigobulhKTTAhXInRoKHRhSDRsQFggk MAA\&url=http\%3A\%2F\%2Fwww.gouvernement.fr\%2Fsites\%2Fdefault\%2Ffiles\%2Fcontenu\%2Fpiecejointe\%2F2016\%2F10\%2Frapport_du_gouvernement_en_application_de_la_convention_internationale_de_ lonu_sur_les_droits_des_personnes_handicapees_.pdf\&usg=AFQjCNFWEsdmrLgGgd8NQIs58Bi49LeddA\&bvm =bv.152479541,d.d2s. Consultado el: 11 nov. 2021.

GUILARTE MARTÍN-CALERO, C. La reinterpretación jurisprudencial de los sistemas de protección a la luz de la Convención de Nueva York: el nuevo paradigma de la Sala Primera. In: GUILARTE MARTìN-CALERO, C. (dir.). Estudios y comentarios jurisprudenciales sobre Capacidad. Madrid: Editorial Thomson Reuters Aranzadi, 2016. p. 59-107. 
LUISIN- PAGNOD, E. Introduction: mais que fait la tutelle. In: LUISING-PAGNOD, E.; SOULARD-PECHBERTY, M.; DURIEZ, F. (dir.). Protéger les personnes vulnérables: regards croisés sur la profession de mandataire judiciare à la protection des majeurs. Paris: Éditorial L'Harmattan, 2014. p. 13-25.

MALAURIE, P. Droit civil: les personnes. La protection des mineurs et des majeurs. 8. ed. Paris: Editorial LGDJ, 2016.

MARTÍNEZ PÉREZ, E. El proceso de polenización de la Convención sobre los Derechos de las Personas con Discapacidad en la jurisprudencia del TEDH. In: GUILARTE MARTİN-CALERO, C. (dir.). Estudios y comentarios jurisprudenciales sobre capacidad. Madrid: Editorial Thomson Reuters Aranzadi, 2016. p. 575590.

MARTÍNEZ DE AGUIRRE Y ALDAZ, C. EI tratamiento jurídico de la discapacidad psíquica: reflexiones para una reforma legal. Pamplona: Editorial Thomson Reuters Aranzadi, 2014.

MATEO SANZ, J. El derecho al honor de las personas con discapacidad. In: GUILARTE MARTİN-CALERO, C. (dir.). Estudios y comentarios jurisprudenciales sobre capacidad. Madrid: Editorial Thomson Reuters Aranzadi, 2016. p. 109-154.

MOLINA TOLEDO, P.; ASTORGA GATJENS, L.; GÓMEZ MOTTA, S. Sin capacidad jurídica no hay derechos humanos: informe de mapeo acerca del ejercicio de la capacidad legal de las personas con discapacidad psicosocial en seis países latinoamericanos. Washington: The Trust for the Americas, 2012. Disponible en: http://corfausam.cl/wp-content/uploads/2012/06/120624-Informe-Final-Mapeo.pdf. Consultado el: 12 nov. 2021.

MOLIN, O. Les tutelles. 3. ed. Paris: Editorial Berger-Levrault, 2017.

NACIONES UNIDAS. Convention relative aux droits des personnes handicapées et Protocole facultatif. [S.I.]: Naciones Unidas, [200-?]. Disponible en: http://www.google.cl/url?sa=t\&rct=j\&q=\&esrc=s\&source= web\&cd=2\&ved=0ahUKEwiwoKSNmLDTAhWEOxoKHZkWAooQFgg2MAE\&url=http\%3A\%2F\%2Fwww. un.org\%2Fdisabilities\%2Fdocuments\%2Fconvention\%2Fconvoptprot-f.pdf\&usg=AFQjCNGEbugsAdUi98106tr6W OaC6ZZGFA. Consultado el: 11 nov. 2021.

NACIONES UNIDAS. Convención Interamericana para la eliminación de todas las formas de discriminación contra las personas con discapacidad. Guatemala: Organización de Estados Americanos, 2011. Disponible en: https://www.oas.org/juridico/spanish/tratados/a-65.html. Consultado el: 22 enero 2022.

NOGUERO, D. Pour la protection à la française des majeurs protégés malgré la Convention des Nations Unies relative aux droits des personnes handicapées. RDSS, Paris, n. 5, p. 964-972, 2016.

ORGANIZACIÓN DE ESTADOS AMERICANOS. Corte Interamericana de Derechos Humanos. Sentencia de 4 de julio de 2006, Ximenes Lopes con Brasil. Magistrado responsável: Antonio Augusto Cancado Trindade, 4 de julio de 2006. Disponible en: http://www.google.cl/url?sa=t\&rct=j\&q=\&esrc=s\&source=web\&cd=1\&ved=0ahU KEwiEIMbiulXUAhXJXhoKHVykCrIQFgghMAA\&url=http\%3A\%2F\%2Fwww.corteidh.or.cr\%2Fdocs\%2Fcasos\%2 Farticulos\%2FSeriec_149_esp.pdf\&usg=AFQjCNE591QGJ0W2ZPvEOb_U6nbuoZNrog. Consultado el: 11 nov. 2021.

PECQUEUR, E.; CARÓN-DÉGLISE, A.; VERHEYDE, T. Capacité juridique et protection juridique à la lumière de la Convention de Nations Unies relative aux droits des personnes handicapées. La loi $N^{\circ} 2007-308$ du 5 mars 2007 est-elle compatible avec l'article 12 de cette Convention?. Recueil Dalloz, Paris, n.17, p. 958, 2016.

ROBERT, P. Le nouveau petit Robert: dictionnaire alphabétique et analogique de la langue française. Paris: Éditorial Le Robert, 2017.

SCHULZE, M. Comprendre la Convention des Nations Unies relative aux droits des personnes handicapées. Lyon: Handicap International, 2010. Disponible en: http://www.google.cl/url?sa=t\&rct=j\&q=\&esrc= s\&source=web\&cd=1\&ved=0ahUKEwiG3b_O2I3TAhUCqxoKHeyTD3QQFggZMAA\&url=http\%3A\%2F\%2Fwww. 
internationaldisabilityalliance.org $\% 2 \mathrm{Fsites} \% 2 \mathrm{Fdefault} \% 2 \mathrm{Ffiles} \% 2 \mathrm{Fdocuments} \% 2 \mathrm{Fcomprendrelacdph}$.pdf\&usg=A FQjCNFljykN8hDlatdgomNIYuzE8M_ezQ\&bvm=bv.151426398,d.d24. Consultado el: 12 nov. 2021.

TEYSSIE, B. Droit civil: les personnes. 18. ed. Paris: Editorial LexisNexis, 2016.

VOIRIN, P.; GOUBEAUX, G. Droit civil. 36. ed. Paris: Editorial LGDJ, 2016. t. 1.

SUIZA. Loi № 2009-1701, de 31 de diciembre de 2009. Féderale sur la création de bases légales pour l'aide financiére allouée aux ressortissants suisses á l'étranger. Berna: Office Fédéral de la Justice. Disponible en: https://www.fedlex.admin.ch/eli/fga/2009/412/fr. Consultado el: 22 enero 2022.

Recebido em: 12.11.2021

Aceito em: 25.12.2021 